\title{
DOSSI色
}

Sociologias, Porto Alegre, ano 3, no 6, jul/dez 2001, p. 30-50

\section{A comunidade científica, o Estado e as universidades, no atual estágio de desenvolvimento científico tecnológico}

MICHELANGELO GIOTTO SANTORO TRIGUERRO *

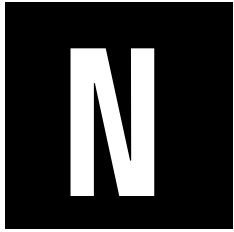

este trabalho, pretendo destacar o papel das comunidades científicas em sua relação com o Estado, no processo de desenvolvimento científico-tecnológico do País. Mais especificamente, discutirei a inserção das universidades neste contexto, focalizando especialmente as instituições públicas.

Em relação ao tema proposto para o presente seminário, buscarei seguir numa posição crítica quanto ao que se convencionou chamar, na literatura, a "tripla hélice", isto é, a articulação entre o Estado, as universidades e as empresas - 0 setor produtivo. A esse respeito, tenciono questionar a validade da utilização desse conceito para explicar a dinâmica do atual desenvolvimento científico-tecnológico brasileiro. Será argumentado que a eficácia explicativa da noção de tripla hélice é limitada para destacar as peculiaridades desse desenvolvimento. Em nosso caso, talvez seja mais adequado falar, não numa dupla, nem numa tripla hélice, mas numa "hélice ênupla (n-upla)", quer dizer, uma múltipla articulação, de enésimo grau, entre instituições e organizações da sociedade, sendo o enésimo ou a ênupla um indicativo de um número bastante grande - " $n$ " - de elementos ou instituições articuladas.

Dentro desta argumentação, pretendo questionar por que apenas três elementos articulados? Por que não explorar muitas outras formas e tipos de combinações, que passam pelas organizações mais conhecidas,

* Doutor em Sociologia pela Universidade de Brasília, professor no departamento de Sociologia da UnB. 
aquelas mencionadas como típicas, mas também por inúmeras outras organizações - não-governamentais e não-empresariais -, por diversos movimentos sociais e vários outros atores, incluindo as inúmeras comunidades científicas nacionais (dos biólogos, físicos, sociólogos, historiadores e de muitos outros, em suas especializações e subdivisões), as quais assumem papel preponderante na dinâmica do desenvolvimento científicotecnológico brasileiro.

Finalmente, pretendo destacar o papel que as universidades poderão assumir no atual contexto, como instâncias mediadoras nas relações entre o Estado e a comunidade científica, bem como entre o Estado e as empresas ou entre o Estado e outras organizações da realidade social. Nesse ponto, serão enfatizados o que considero os principais obstáculos a serem enfrentados internamente pelas universidades, para poderem enfrentar adequadamente os novos desafios impostos pela realidade atual e pela nossa ciência e tecnologia.

Inicialmente, a noção de comunidade científica é bem específica. Não se refere, aqui, a qualquer grupo de pesquisadores que se reúnem informalmente ou que discutem seus trabalhos em fóruns ou congressos, como um grupo de amigos. Trata-se, ao contrário, de um conceito sociológico muito difundido em toda a tradição da sociologia da ciência, embora não exista consenso nessa conceituação.

Sem entrar nas variações a respeito dessa noção, na literatura, entre, por exemplo, uma linha estrutural-funcionalista - na perspectiva de Robert M erton -, que destaca o seguimento às normas vigentes entre os cientistas, e outra, baseada na competição e na disputa pela hegemonia no "campo científico", como nos trabalhos de Pierre Bourdieu a esse respeito, há um núcleo comum que ressalta a existência de regras, valores e sanções entre os praticantes de uma ciência, configurando uma instituição social específica. Nesse sentido, a instituição social da ciência pressupõe uma comunidade científica, ou muitas, se considerarmos as várias áreas do conheci- 
mento científico, cada uma das quais com um "ethos" próprio, ainda que se pautando em princípios e padrões de conduta mais universais, referentes à instituição científica como um todo.

Para muitos sociólogos da ciência, a noção de comunidade científica ou de "campo científico", nos termos de Bourdieu, é central na compreensão e explicação do modo como se organiza a atividade científica, e são produzidos novos conhecimentos. Q uer dizer, nessa linha, a ciência é explicada e interpretada a partir do entendimento do funcionamento e da dinâmica interna da comunidade científica, analisando, por exemplo, o que está em jogo, quaisas prioridades de pesquisa, onde são divulgados os seus resultados, como são selecionados novos membros, como são tratadas as demandas externas, particularmente aquelas que provêm do Estado, e assim por diante. Enfim, nessa abordagem, o entendimento desses aspectosé fundamental para se compreender a própria ciência, em seus resultados e em sua organização social.

Contudo, recentemente, autores identificados com a corrente do chamado "construtivismo" na sociologia da ciência, a exemplo de Karin Knorr-Cetina, vêm criticando essa suposta centralidade do conceito de comunidade científica, entendendo que, nas situações concretas de pesquisa, nos laboratórios, a prática científica é sujeita a inúmeras outras ordens de influências, não apenas internas ou atinentes a um campo epistêmico em particular, mas referidas a uma constelação de interesses os mais diversos, envolvendo cientistas e não-cientistas, técnicos, políticos, empresários, dirigentes de órgãos públicos e vários outros atores. É o que a autora acima conceitua como as "arenas trans-epistêmicas", na atividade científico-tecnológica. N essas arenas, ou nas "networks" de Bruno Latour, os cientistas precisam negociar, "transladar interesses", a fim de conseguirem as condições e os recursos necessários para a realização do seu trabaIho. Ao final, dizem os autores dessa abordagem, os fatos científicos não consistem em racionalizações estritas, não são resultados puramente cognitivos, unicamente provenientes de uma racionalidade "técnico-ins- 
trumental", para usar a expressão de Max Weber, mas decorrem de um sistema amplo de combinações de interesses, representações, negociações e decisões, com atores e circunstâncias as mais variadas, ou seja, são processos e resultados eminentemente sociais, carregando para os fatos científicos toda uma dimensão humana, econômica, cultural e política, não se restringindo a meras operações técnicas ou lógicas.

Mas o que toda essa discussão tem a ver com o objeto de nossa reflexão? Tudo. Ao se destacar a não-proeminência ou a não-exclusividade do constructo comunidade científica na explicação da ciência e do desenvolvimento tecnológico, com base nas abordagens apontadas anteriormente, pretendo insistir que precisamos buscar outros quadros analíticos para dar conta das inúmeras injunções e articulações que hoje sustentam e condicionam toda a prática científico-tecnológica. Atualmente, sobretudo em áreas de ponta do conhecimento como as dos novos materiais, química fina, robótica, engenharia aeroespacial, informática, microeletrônica e biotecnologia, é fundamental termos claro que não se trata de campos estanques do conhecimento, áreas isoladas, mas, ao contrário, muito articuladas, envolvendo diversos atores e interesses, econômicos, políticos e sociais, haja vista, sobre este último aspecto, a polêmica levantada em torno dos transgênicos.

Em suma, a comunidade científica não é a única envolvida nessas atividades e talvez nem seja, em muitos casos, a mais importante, a julgar pela dinâmica recente envolvendo grandes interesses empresariais, que pressionam antigas formas e padrões de organização das próprias comunidades científicas. N esse sentido, vale lembrar os poderosos interesses que se superpõem aos dos acadêmicos, especialmente nessas áreas dos conhecimentos. Vejamos, por exemplo, a grande influência dos fármacos, das empresas produtoras de sementes, dos grupos petroquímicos e tantos outros exemplos. Diriam alguns, "a ciência e a tecnologia são coisas muito sérias para ficar somente nas mãos dos pesquisadores". 
E todo este questionamento ressalta um outro lado muito importante na presente discussão, que se refere à problemática da legitimação em torno do desenvolvimento científico-tecnológico. Este tema, por si só, justifica intensas discussões, com a participação de muitos outros públicos presentes na sociedade. Refiro-me especificamente a um questionamento a respeito dosnovos rumos do nosso desenvolvimento científico-tecnológico e de como a sociedade pode interferir nesses acontecimentos, o que requer muita informação - e de fácil acesso ao grande público -, com a participação da mídia e, especialmente, dos cientistas, esclarecendo os reais resultados alcançados, os riscos envolvidos e as potencialidades em termos de emancipação humana.

Entretanto tudo isso não significa negar a importância dos cientistase dos conhecimentos especializados e técnicos. 0 que pretendo destacar é que, no quadro atual do desenvolvimento científico-tecnológico, esquemas apoiados unicamente na compreensão da dinâmica dos pares de cientistas e dos seus interesses - aquilo que se pode criticar como visão excessivamente endógena - são amplamente insuficientes para entender a nossa realidade nesse campo da investigação.

Seguindo essa estratégia de análise, a chamada abordagem da tripla hélice preconiza a necessidade de visões mais integradas, envolvendo, nesse caso, o Estado, as universidadese as empresas. Contudo, conforme mencionei anteriormente, a própria noção de tripla hélice parece limitada. São, na verdade, muitos outros grupos de atores e organizações que, dependendo das circunstâncias e da dinâmica das relações estabelecidas em cada formação social concreta, podem compor redes muito mais complexas e ampliadas de interesses. Além disso, é possível que, em dada situação concreta, um dos atores proeminentes não sejam as universidades, ou o Estado ou ainda as empresas, mas determinados movimentos sociais, como, por exemplo, os ambientalistas. N este exemplo, tais grupos podem exercer fortes pressões por novas trajetórias científicas ou tecnológicas, buscando a utilização 
racional dos recursos naturais, numa visão mais holista e abrangente, a respeito da relação homem-natureza, que a tipicamente reducionista da biologia molecular e das técnicas de manipulação genética. O u pode ser o caso de uma cooperativa de agricultores ou de uma organização não-governamental que passe a comandar o curso de determinadas pesquisas em suas áreas de interesses. Nessa situação, o olhar macro e a lógica estritamente capitalista podem não ter condição política, a legitimação, e apoio suficiente para progredir em suas pesquisas, ainda que existam interesses empresariais, apoio do Estado e grupos capacitados em universidades.

Insisto na necessidade da não-reificação dos constructos analíticos. 0 que se exige é o exame concreto das situações, caso a caso, sem desconhecer o potencial explicativo dos modelos e dos quadros teóricos mais abrangentes, para não se cair numa perigosa armadilha de considerarmos errada a realidade, simplesmente por não se ajustar a determinado esquema classificatório ou a algum modelo explicativo previamente concebido. Se, de um lado, esta atitude não implica, necessariamente, o mero alijamento de quadros mais abrangentes e modelos teóricos gerais, o que parece sempre necessário, por outro lado, não significa a adesão automática ao modelo ou ao conceito formulado, o que pode ocorrer nesse caso, na ênfase exclusiva à noção de comunidade científica ou na insistência ao modelo da tripla hélice. Reivindico, ao contrário, a análise de relações que não se restringem ao esquema analítico aludido anteriormente e a busca do exame de situações concretas que passa pelo olhar histórico nos acontecimentos e processos que constituem objeto de nossa reflexão no presente momento.

Seguindo esta linha de preocupações gostaria de destacar, no caso brasileiro, primeiramente, não a relação entre as universidades e o Estado, mas entre este e as comunidades científicas.

0 argumento que pretendo fundamentar reside no entendimento de que, na realidade brasileira, as relações entre o Estado e as comunidades científicas são as relações fundamentais para compreender os caminhos e 
descaminhos do nosso desenvolvimento científico-tecnológico. Aqui as universidades se constituem em atores secundários nesse desenvolvimento.

0 que quero dizer é que as universidades não representam, no caso brasileiro, um dos três elementos propulsores, como preconizado pelo modelo da tripla hélice, para o desenvolvimento científico-tecnológico. Elas são instâncias importantes, onde são localizados valiosos grupos de pesquisa e laboratórios. Muito de nossa pesquisa passa por dentro das universidades, mas estas não são, como tais, atores proeminentes no referido processo de desenvolvimento. $\mathrm{N}$ ão são as pró-reitorias, as reitorias, os decanatos, os institutos, os departamentos que configuram o eixo dinâmico do avanço científico-tecnológico nacional.

As universidades, como organizações complexas, constituem, além do abrigo e da sede de muitos grupos de cientistas, o espaço de muitos outros interesses ligados ao ensino, aos serviços prestados à sociedade, aos movimentos discentes, docentes e de técnico-administrativos, e assim por diante. Assim, elas não se constituem nos atores, por excelência, da dinâmica científico-tecnológica brasileira. Antes, são as comunidades científicas, em sua relação com o Estado, que assumem um dos pólos desta condição de vanguarda.

Estas últimas, sim, sobrepassam as próprias universidades, estão acima e além delas. E é claro que não estou referindo-me unicamente às práticas de pesquisa como tal, que se constituem em extensas redes de relações, como aliás já mencionado neste trabalho, porém, refiro-me ao peso e à atividade eminentemente política dessas comunidades, junto, sobretudo, ao Estado nacional, na busca de consolidar posições hegemônicas, num ambiente de muitas disputas por recursos os mais diversos - materiais e simbólicos.

Neste contexto, não são as comunidades científicas, sozinhas, que passam a ter um papel proeminente em nosso desenvolvimento científicotecnológico, conforme procurarei destacar mais adiante, mas são as rela- 
ções entre estas e o Estado, numa combinação de interesses e necessidades específicas, uma forma de mutualismo, que dão sentido e coerência a todo o processo em que se constitui e se consolida a nossa base científicotecnológica. Neste particular, as universidades passam ao largo. 0 que pode até explicar muitas das contradições entre o Estado e as universidades, quando se examina este tema à luz do progresso verificado em muitos campos do conhecimento.

Isso não significa "desmaterializar", por assim dizer, as nossas bases científico-tecnológicas, retirando delas o seu lócus, mas apontar as instâncias efetivamente reguladoras de tais bases - nos níveis de regulação política das relações entre os inúmeros grupos e comunidades científicas nacionais e o Estado.

Vejamos rapidamente a constituição deste processo, destacando os acontecimentos mais recentes, especialmente a partir de meados da década de sessenta e início da década de setenta, no País.

Nos anos 70, o Brasil vivia o governo militar, que se instalou em 64, passando a conduzir o País com decisões centralizadas, de implementação planejada e autoritariamente impostas à população. Era o momento do planejamento governamental e de ampliação da ação direta do Estado em diversas dimensões da sociedade, incluindo a educação, a C\&T e a economia, dando origem ao conceito de burguesia estatal, cunhado pela sociologia de então (Figueiredo, 1978).

O nacionalismo dos militares no governo preferia ampliar os investimentos governamentais, pretendendo, assim, reduzir a entrada de capital estrangeiro. As empresas multinacionais já se expandiam a passos largos (Barnet \& M uller, 1974), mas os efeitos da chamada revolução científicotecnológica não se faziam sentir com clareza em nosso País, em termos do que veio a ser posteriormente identificado como processo de globalização.

1 Neste ponto do trabalho, irei basear-me num texto escrito por mim e por Vilma Figueiredo, intitulado 0 desenvolvimento científico-tecnológico atual; globalização e democratização: dilemas e perspectivas, de 1998 
O "milagre brasileiro" e seus índices alvissareiros de crescimento no início dos anos 70 foi o resultado dessas ações, tendo sofrido o primeiro grande abalo com a crise internacional do petróleo de 73/74. Fielmente ao estilo da época, o governo respondeu com decisões, mais ou menos bem sucedidas, apresentadas como de razão exclusivamente técnica, implementadas por meio de planos e ações, a exemplo do proálcool e do programa nuclear.

U m governo de decisões autoritárias, com forte apelo nacionalista/ patriótico e apoiado no planejamento centralizado, favoreceu, na sociedade civil, o fortalecimento da cultura clientelista e a organização da pressão corporativa de afirmação política.

Assim é que, apesar do controle autoritário exercido sobre a sociedade, muitos anseios de frações e grupos sociais puderam concretizar-se. Os avanços na expansão do sistema de $C \& T$ são um bom exemplo de realização de interesses de uma comunidade científica que aprendeu a se organizar e a usar as armas políticas adequadas ao momento.

É de notar, sob esse aspecto, a inflexão de ênfase no papel da Sociedade Brasileira para o Progresso da Ciência (fundada em 1948), que passou, a partir do final dos anos 60, a ter uma atuação muito mais política, chegando a se constituir, nos anos 70 , num dos raros espaços de crítica ao governo e de expressão de interesses sociais.

Com essa atuação, a SBPC, juntamente com a Academia Brasileira de Ciências (criada em1916), passou a ser um ator político cuja expressão não pode ser ignorada por um governo patriótico e de intenções modernizadoras. A ação da SBPC e da ABC foi definitiva, por exemplo, na reestruturação do CN Pq, em 1974, quando se afirmaram os comitês assessores, e demais ajustes posteriores do órgão, ampliando a participação direta da comunidade científica nos processos decisórios internos e na implementação e formulação da política de C\&T.

Essas duas sociedades científicas estiveram igualmente presentes na criação da FINEP, em 1969, e do Fundo Nacional de Desenvolvimento 
Científico e Tecnológico (FNDCT), em 1971, por ela gerido. Desde esse período, a SBPC e a ABC passaram a ser atores cruciais do sistema de C\&T, cujo apoio tornou-se imprescindível à formulação e ao êxito das políticas para o setor (Figueiredo e Garcia, 1997).

A implantação generalizada da pós-graduação, a partir do final dosanos 60 , só foi possível pela colaboração entre governo e comunidade científica.

Em 1976, por exemplo, a CAPES introduziu o sistema de "avaliação por pares", em pleno acordo com setores relevantes da comunidade e com o aval das maiores sociedades científicas.

No planejamento (concepção e implementação) de $C \& T$, a comunidade científica, através de suas sociedades representativas, passou a ser elemento fundamental. 0 primeiro Plano Nacional de Pós-Graduação foi aprovado para o período 75/79 e, com ele, o Plano Institucional de Capacitação de Docentes (PICD).

0 final dos anos 70 foi palco da proliferação de sociedades e associações político-profissionais variadas, inclusive científicas. É desse período a criação generalizada de associações de docentes, de associações profissionais, até mesmo de profissões ainda não reconhecidas, com o fito de tornálas reconhecidas e regulamentadas, como as de sociólogos. Era a busca de proteção e de defesa dos interesses das diferentes corporações profissionais.

A comunidade científica não fugiu à regra. Diferentes áreas do conhecimento reativaram suas sociedades ou criaram novas, de modo a poderem representar as particularidades das diversas ciências e os interesses de seus praticantes. Esse processo foi bastante facilitado com o estímulo, especialmente por parte da CAPES, de criação de associações nacionais de pesquisa para as áreas que se organizavam.

De finais de 70 até os anos 80 , as associações de pesquisa proliferaram nas diferentes áreas do conhecimento. As humanidades e as ciências sociais, apesar de se fazerem abrigar na SBPC, não tinham a voz ativa que passaram a ter depois de organizadas nessas associações. 
O II e III Planos Nacionais, de 82/85 e 86/89, contaram com intensa colaboração dessas novas sociedades científicas. As indicações de membros para comitês, comissões, conselhos passaram a ser feitas mediante consultas a elas. A criação do M inistério de Ciência e Tecnologia, em 1985, passou pelas sociedades científicas. O M inistério e as Presidências dos órgãos governamentais do sistema de C\&T sustentam-se com o aval da comunidade científica organizada em suas sociedades e associações.

A grande expansão do sistema de $C \& T$ a partir de final dos anos 60 foi induzida pelo governo através de suas agências de fomento da pesquisa, tanto federais como estaduais, por meio de ações planejadas e executadas com a colaboração da sociedade científica. CNPq, CAPES, FINEP e, posteriormente, as Fundações Estaduais de Apoio à Pesquisa (apenas a de São Paulo antecede esse período) contam com a participação direta da comunidade científica em diferentes níveis.

Assim, é inegável o efeito modernizante produzido pela comunidade científica sobre o sistema de $C \& T$, quer por meio de atuação direta de seus representantes ou por pressões exercidas sobre o governo. Inegável, também, é que essa atuação forjou-se num quadro de dominação da cultura política clientelista, associada a ações corporativas de indivíduos e grupos, ambas favorecidas pelo regime autoritário-militar.

Há, portanto, que reconhecer na ação dos cientistas no Brasil, no final dos anos 60 até meados dos 80 , forte marca corporativa. E isso, principalmente, no que emanava das associações profissionais de cientistas (por exemplo, as associações de docentes universitários), mas também das propostas das sociedades científicas propriamente ditas.

Se a pressão corporativa mostrou-se eficaz no quadro da clientela política dos governos militares e de suas ações planejadas, as mudanças ocorridas no mundo e no País a partir de meados dos anos 80 tornaram tais práticas inadequadas, se bem que resistentes à superação.

Os desafios da inserção produtiva num mundo globalizado - que implica, necessariamente, avanços científicose tecnológicos - e as deman- 
das econômicas e sociais de uma sociedade com projeto democrático tornam obsoletas as pressões corporativas de afirmação política. Inegavelmente, durante as últimas décadas, a comunidade científica brasileira tornou-se ator político relevante, necessário tanto para o aprimoramento do sistema de C\&T como para o amadurecimento democrático do país. Agora e no futuro próximo, porém, a importância política da comunidade científica - para o país, para a ciência e para os próprios cientistas - vai depender de seu reajuste aos novos tempos.

Em primeiro lugar, a ação governamental apoiada no planejamento centralizado não mais tem eficácia nem viabilidade no momento atual. Vive-se a época da decisão compartilhada, de um planejamento participativo, em que novos atores passam a ocupar a cena política e aprendem a enfrentar o desafio da convivência com a diferença.

Em outras palavras, está superada a fase do domínio da "razão técnica" como justificativa para imposição de decisões de governo, e ensaia-se a prática política da negociação democrática. Esta requer de seus agentes- no governo e na sociedade civil - uma visão não-fragmentária do todo social que informe interesses coletivos complexos e não-particularistas. A comunidade científica e suas associações representativas encontram-se frente a tais questões.

Juntamente com a superação do planejamento centralizado, o financiamento estatal das ações e instituições públicas encontra seu limite quando o interesse público e os direitos do cidadão se ampliam. Além das privatizações de empresas estatais, a ampliação da participação do capital privado faz-se necessária de modo a tornar possíveis o volume e a qualidade dos serviços prestados à sociedade. Essas demandas são largamente ampliadas com o desenvolvimento econômico e o avanço da democracia. E desse processo não fogem os serviços vinculados ao sistema de $C \& T$, cujo financiamento vai passando a incluir múltiplas fontes, estatais e privadas.

Há quatro anos, o então Presidente do CNPq, apresentando a sinopse das despesas da U nião com C\&T, declarava que o Governo Federal constitui a mais importante fonte de recursos para a Ciência e Tecnologia, representan- 
do uma parcela superior a cinqüenta por cento dos dispêndios de todas as fontes nacionais (Tundisi, 1995). Em 1998, o Ministro de Ciência e Tecnologia anunciara crescimento absoluto e relativo dos investimentos em $C \& T$ (em 1992, representavam 0,53\% dos R $\$ 600$ bilhões do PIB e em 97 passam a $1,2 \%$ dos R $\$ 830$ bilhões do PIB) e destacara os 127 projetos privados em andamento nos setores industrial e agropecuário, representando investimentos da ordem de $R \$ 2,12$ bilhões. Alvissareiro esse crescimento da iniciativa privada na $C \& T$, mas necessita de significativa ampliação.

O financiamento múltiplo do sistema de $C \& T$, com recursos públicos estatais e significativo aumento dos privados, passou a ser uma exigência dos tempos atuais e tende a beneficiar até mesmo o amadurecimento das próprias sociedades científicas brasileiras, que ainda dependem quase que exclusivamente de recursos públicos estatais.

N esse período, surge a ênfase na distinção entre conceitos de coisa pública e de coisa pública governamental: instituições, entidades, financiamentos e interesses públicos não são necessariamente federais, estaduais ou municipais.

O destaque dessa distinção empreendida pelas ciências da sociedade coaduna-se com demandas e propósitos políticos da transição democrática. A ampliação dos direitos e a extensão de serviços e benefícios públicos a um número crescente de camadas sociais torna inviável sua sustentação exclusivamente pelo Estado.

À expansão quantitativa do sistema de $C \& T$ no período anterior deverá corresponder um aumento na qualidade nos anos 90 em diante. 0 aprimoramento na qualidade no sistema de $C \& T$ inclui, obviamente, maior eficiência na utilização dos recursos e melhor qualidade dos produtos gerados, o que reforça a necessidade do aprimoramento de processos periódicos de avaliação.

Além disso, no momento atual, a melhora de qualidade associa-se, também, à maior transparência do sistema, ao atendimento de demandas sociais e à prestação de contas à sociedade. 
Tais pressões sobre $C \& T$ não são particularidades brasileiras. Em todos os países da atualidade onde se desenvolveu um sistema de $C \& T, 0$ controle social sobre ele aumentou. $N$ ão há mais possibilidades de investimento garantido na ciência pela pura justificativa do possível rompimento de barreiras do conhecimento. O s exemplos do Japão e do Sudeste Asiático são eloqüentes para mostrar que investimentos substanciais na pesquisa básica não são condição suficiente e, talvez, nem mesmo necessária para assegurar inovações bem sucedidas no mercado. N os Estados U nidos, a mudança de atitude é claramente revelada no relatório Science in the National Interest (Clinton \& Gore, 1994) no qual a questão não é mais empurrar as fronteiras do conhecimento na esperança de que a sociedade possa disso se beneficiar em algum momento no futuro, mas, tão rapidamente quanto possível, usar o conhecimento existente para resolver os mais urgentes problemas econômicos, industriais, comerciais e sociais.

Q uando a pauta de prioridades fica carregada, a necessidade do desenvolvimento científico tem que se fazer clara, de modo a atrair para a ciência investimentos que poderiam fazer-se em outros domínios: é a disputa democrática por recursos. No dizer de Jean-Jacques Salomon, do Centre Science,

Technologie et Société de Paris, se bem que a ciência faça parte da cultura e como tal possa parecer ter um fim em si mesma, as atividades de $P \& D$ são, de fato, instrumentos usados para objetivos extra-científicos - são esses os objetivos que moldam o futuro da sociedade, e não o contrário... (Salomon, 1996).

E não somente o contexto internacional, mas também a sociedade brasileira se tornara mais complexa nestas últimas décadas do século. São avanços científico-tecnológicos reestruturando processosindustriais, reconstruindo relações sociais e gerando novos atores, que respondem às mudanças ocorridas e que orientarão, por sua vez, o curso dos avanços e das transformações futuras. 
Ao Estado, dadas as demandas de uma sociedade democrática, não caberão mais as responsabilidades de financiamento exclusivo do também complexo sistema produtor de ciência e de tecnologia.

Dentre os atores de $C \& T$, chamou-se, já, atenção para a crescente participação do empresário no processo de geração de conhecimentos, especialmente no de inovações tecnológicas. 0 empresariado no Brasil, que relativamente a outros países tem sido um ausente no processo, dá indícios de se estar tranfformando em um ator relevante na área de produção de C\&T (Figueiredo \& Araújo, 1998), deixando de ser apenas um consumidor protegido por guarda-chuvas governamentais.

O quadro descrito anteriormente evidencia, de um lado, a importância do papel assumido pelas comunidades científicas brasileiras, em sua relação com o Estado. Porém, de outro lado, abriga uma realidade bastante incompatível com as novas necessidades impostas pelas transformações sociais recentes, em particular aquelas decorrentes do próprio desenvolvimento científico-tecnológico. U ma das distorções que podem ser verificadas refere-se às grandes disparidades e desigualdades produzidas no País, em termos da distribuição de nosso potencial científico-tecnológico. A esse respeito, os eixos sul e sudeste concentram mais de $60 \%$ de toda nossa capacidade científica e tecnológica, segundo informações obtidas junto ao CNPq. As demais regiões ficam com o restante, vacilando entre a sobrevivência e a necessidade de responder aos imensos desafios que pesam sobre elas, provenientes de vários setores. U m desses exemplos pode ser visto no tema da biodiversidade, quando a região norte, que não tem sido contemplada devidamente por parte do Estado em termos de garantia e mesmo expansão dessa área temática, passa a representar um espaço estratégico, uma vez que abriga em suas fronteiras grande parte da disponibilidade de recursos genéticos, medicinais e farmacêuticos. 0 que fazer nesse caso, para reverter o quadro e propiciar novas oportunidades de avanço do conhecimento? 0 mesmo pode-se dizer do nordeste, por exemplo, no que tange ao tema dos 
recursos hídricos. O u na região do pantanal mato-grossense, no tema do aproveitamento do potencial piscoso e no controle da fauna.

Em suma, a concentração do nosso potencial científico-tecnológico no sul e sudeste, resultado do jogo político dos grupos hegemônicos das comunidades científicas nacionais, com a conivência do Estado, tendeu a reforçar a realidade díspare ente nossas regiões, produzindo uma situação, no presente momento, difícil de ser revertida. Para isso, seria absolutamente indispensável maior independência e autonomia por parte do Estado, a fim de poder exercer ação regulatória mais efetiva e formular políticas mais conseqüentes para a área científico-tecnológica nacional. 0 que requer enfrentar inúmeros entraves e grandes obstáculos com as comunidades científicas, especialmente com os grupos hegemônicos, ciosos de continuarem a dar as cartas nesse terreno. Como superar essa realidade é uma questão aberta e de difícil solução, porém absolutamente incontornável.

$\mathrm{Na}$ busca de superar esses entraves, o Estado busca maior aproximação e inserção com setores empresariais, conforme comentei anteriormente, mas também esbarra em outros bloqueios, apontados como dificuldades históricas e culturais envolvendo as comunidades científicas e o meio empresarial. São lógicas distintas, orientadas por princípios e práticas muito diferentes e que acabam por dificultar caminhos promissores de relações entre ambos os setores.

Faltam aos nossos empresários maior convicção e determinação em investir em pesquisas e no desenvolvimento tecnológico, segundo opinião corrente entre os cientistas. De sua parte, os empresários criticam a lentidão e a falta de resultados práticos mais efetivos por parte dos pesquisadores. Enfim, parecem mundos estranhos, realidades à parte.

Como vencer, novamente, esses obstáculos?

Sem pretender defender qualquer fórmula salvadora ou solução mágica para esses impasses, uma vez que são situações muito complexas e sujeitas a um jogo político de grandes embates e interesses, gostaria de 
concluir essa reflexão destacando a necessidade, não apenas de o Estado brasileiro, crescentemente, vir a assumir maior independência e autonomia para desenvolver o seu efetivo papel regulatório e normativo relativamente às comunidades científicas, mas de se destinar e redimensionar, de modo muito mais ativo que o observado até então, o importante papel que cabe às universidades nesse contexto.

Em outras palavras, não basta o Estado investir em mecanismos avaliativos mais efetivos e forçar as universidades a buscar a melhoria da qualidade interna, de seus cursos, de suas práticas acadêmicas em geral. Faz-se mister, também, mudar estratégias nas políticas científicas e tecnológicas, emulando as universidades a assumirem uma condição de instâncias mediadoras, não apenas como abrigo ou residência para os vários grupos de cientistas que nelas se apóiam para desenvolverem suas atividades, mas como atoresimportantes, formulando projetos institucionais globais, definindo e redefinindo prioridades de pesquisa, em consonância com as políticas governamentais e com as realidades locais, da região e do País, e, enfim, formulando e implementando ações de parceria junto a vários setores da sociedade, sejam estes empresariais, movimentos sindicais, organizações não-governamentais e assim por diante. Desse modo, poderemos falar, então, não apenas em tripla hélice, mas, como já referido, em hélices ênuplas, de múltiplas articulações e possibilidades.

Este papel destacado para as universidades enquanto instâncias mediadoras das relações entre o Estado e as comunidades científicas ou entre o Estado e as empresas requer maior autonomia e independência para aquelas instituições, semelhantemente ao que defendi para o Estado. $\mathrm{Ou}$ seja, também com relação às universidades, a exigência de ações mais propositivas no delineamento e implementação de atividades científicas e tecnológicas passará a demandar que suas políticas internas não sejam meras extensões do desejo e dos interesses das comunidades científicas presentes em seu interior, especialmente dos seus grupos hegemônicos. 
Sem essa condição, as universidades permanecerão atreladas à lógica dos grupos de cientistas, que nem sempre se coaduna com novas necessidades e demandas sociais, como as que presenciamos no atual contexto da sociedade e do avanço científico. Ou seja, nem sempre os interesses corporativos das comunidades científicas podem ajustar-se a novas prioridades que se originam no interior da sociedade e atinentes a novos cursos e opções de desenvolvimento para o País. O que não exclui, obviamente, toda a imensa contribuição de nossa ciência e tecnologia nessas últimas décadas, em várias áreas, na pesquisa agropecuária, na área médica, na dos fármacos, na engenharia aeroespacial e nas humanidades. Neste ponto, estou ressaltando na verdade a necessidade de aliar qualidade acadêmica com relevância social, rigor teórico e conceitual com demandas sociais, custo com benefício.

Numa nova situação a ser assumida pelas universidades, a própria relação com o meio empresarial pode ser também facilitada. O u seja, as universidades também podem ser instâncias mediadoras importantes entre as comunidades científicas e as empresas. 0 que se constata, hoje, como de difícil interação, a despeito do esforço governamental mencionado anteriormente, poderia ser enfrentado e superado mediante programas desenvolvidos pelas próprias universidades. As incubadoras de empresas são ótimos exemplos nesse sentido. Porém muito mais poderá ser feito nessa área.

Falando desse modo, parece que as transformações aventadas são puramente voluntaristas: basta as universidades assim desejarem, que os problemas aqui apontados poderão ser superados. Evidentemente que não é desse modo. Há limites estruturais importantes, entraves políticos, vícios internos acumulados ao longo de anos nas universidades, imensos bloqueios de comunicação, processos decisórios lentos e excessivamente burocratizados e a dificuldade de ordem material de todo o tipo. É um caminho bastante espinhoso e que requer muita determinação e coragem por parte dos 
principais dirigentes dessas instituições. Os próprios grupos científicos, que detêm a hegemonia política nas universidades, e as contradições e interesses no bloco de poder nessas instituições, em geral conservadorese infensos a grandes mudanças, é um fator de inércia importante a ser considerado.

Contudo, a julgar pelo que tenho visto em minhas pesquisasnessa área, constatam-se muitas experiências inovadoras, sobretudo entre as chamadas universidades comunitárias; experiências estas que podem ser multiplicadas.

Além disso, a proliferação de instituições particulares de ensino superior parece ter aberto novos espaços de concorrência e disputa por novas oportunidades, o que poderá produzir conseqüências importantes no destino das universidades brasileiras, especialmente entre as públicas - hoje responsáveis pela maior atividade científica e tecnológica entre as instituições de ensino superior no País.

Em suma, o momento é propício para novosarranjos organizacionais, novas possibilidades de atuação concreta na realidade científico-tecnológica. Igualmente, muitos são também os desafios; são diversos os problemas acumulados e muitos os méritos. No momento, faz-se mister ampliar 0 debate, aprofundar a discussão e buscar alternativas promissoras num cenário que apenas delineia os seus primeiros sinais.

\section{Referências bibliográficas}

CALLO N , M . \& LATOU R, B. La science telle qu'elle se fait. Paris: La Dècouverte, 1991.

CALLO N, M. La science et ses reseaux; genèse et circulations des faits scientifiques. Paris: La Découverte, 1989.

CAN O N, F. Les révolutions industrielles du XX siècle. Paris: Albin M ichel, 1997.

CLINTON \& GORE. Science in the national interest. W ashington: Executive O ffice of the President. OSTP, 1994. 
FIGUEIRED O, Vilma. Desenvolvimento dependente brasileiro. Rio: Zahar, 1978.

FIGUEIRED O, Vilma \& ARAÚJO, Caetano Ernesto P. de. A liderança empresarial no DF. Relatório de Pesquisa apresentado ao CN Pq em fevereiro de 1998.

FIGUEIREDO, Vilma \& GARCIA, M aria Lúcia. A brasileira em uma perspectiva comparada. In: Pós: Revista Brasiliense de Ciências Sociais. Braślia, ICS/U nB, Ano I, Vol I, n.1, 1997.

GIBBO NS, M.; LIMO GES, C.; NOWOTNY, H.; SCHWARTZMAN, S.; SCOTT, P. \& TRO W, M. The new production of knowledge: the dynamics of science and research in the contemporary societies. London: Sage, 1994.

KN O RR-CETINA, K. Scientific comunities or transepistemic arenas of research? A critique of quasi economic models of science. In: Social Studies of Science, 12, 1982, p. 101-130.

KN O RR-CETINA, K. The manufacture of knowledge: on essay an the constructivist and contextual nature of science. Oxford: Perzaman Press, 1981.

LATO UR, B. Give me a laboratory and I will raise the world. In: KN O RR-CETINA, k. \& MULKAY, M. Science O bserved. London: Sage, 1983.

SALOMON, Jean-Jacques. The future of research policies: the endless frontier revisited. In: II Jornadas Latino Americanas de Estudios Sociales de la Ciencia y la Tecnologia, 1996.

TRIGUEIRO, M. Legitimação na produção científico-tecnológica. In: Sociedade e Estado, Volume VII, N úmeros 1 e 2, jan./dez, Departamento de Sociologia-UnB, Brasília, 1992.

TRIGUEIRO, M. O que foi feito de Kuhn? O construtivismo na sociologia da ciência; considerações so bre a prática das novas biotecnologias. In: SO BRAL, F.; M ACIEL, M. \& TRIGUEIRO, M. A alavanca de Arquimedes: ciência e tecnologia na virada do século. Braślia: Paralelo 15, 1997. 
Sociologias, Porto Alegre, ano 3, no 6, jul/dez 2001, p. 30-50

TRIGUEIRO, M. A Avaliação Institucional nas U niversidades Brasileiras: diagnóstico e perspectivas. (mimeo.) Brasília: CRUB, 1998.

TUNDISI, José Galizia. Despesa realizada da união em ciência e tecnologia sinopse. MCT, CNPq, dezembro de 1995.

\section{Resumo}

0 trabalho discute a relação entre a comunidade científica, o Estado e a universidade no contexto atual do desenvolvimento científico-tecnológico. Enfatiza a dimensão política das transformações recentes, sobretudo no tocante aos sistemas decisórios, contrapondo momento mais verticalizado com cenário mais democratizado, e as conseqüências das transformações políticas contemporâneas, na sociedade brasileira. Procura analisar as mútuas correlações entre o Estado, as universidades e as comunidades científicas, a partir do entendimento da especificidade de cada um destes atores na condução do desenvolvimento científico-tecnológico nacional. A esse respeito, é analisado todo um conjunto de ações que se coadunam com o novo modo de produção do conhecimento, buscando destacar a natureza controversa e polêmica da inserção do Estado e o caráter conservador da comunidade científica, bem como a resistência da universidade na proposição de novas linhas de atuação no enfrentamento dos desafios trazidos pela ciência e tecnologias contemporâneas.

Palavras-chave: Tecnologia moderna, novo modo de produção do conhecimento, política científica e tecnológica. 